\title{
REVIEW
}

\section{Human Melanoma Antigens Recognized by T Lymphocytes}

\author{
Yutaka Kawakami, Paul F Robbins and Steven A Rosenberg \\ Surgery Branch, National Cancer Institute, National Institutes of Health, Bethesda, MD, USA
}

(Received for publication on December 21, 1995)

\begin{abstract}
Human melanoma antigens and their epitopes recognized by $\mathbf{T}$ cells have been identified using a variety of methods. These antigens are classified as 1) melanocyte specific melanosomal proteins (MART-1, gp100, tyrosinase and TRP-1), 2) proteins expressed in testis and a variety of cancers (MAGE-1, MAGE-3, BAGE and GAGE), 3) tumor specific mutated proteins (B-catenin, MUM-1 and CDK4), and 4) others (p15). Some of the HLA-A2 binding non-mutated melanoma epitopes contained non-dominant anchor amino acids and have relatively low HLA-A2 binding affinity, suggesting that these epitopes were likely to be subdominant or cryptic self determinants. The significant correlation observed between vitiligo development and $\mathbf{I L}$ based immunotherapy suggested that autoreactive $\mathbf{T}$ cells specific for these self peptides were involved in melanoma regression in vivo. In addition, since adoptive transfer into patients of CTL recognizing these epitopes resulted in tumor regression, these epitopes may be tumor rejection antigens. Melanoma reactive CTL were efficiently induced from PBL of patients by in vitro stimulation with PBMC pulsed with these melanoma epitopes and may be useful in adoptive transfer protocols for the treatment of patients with metastatic melanoma. An immunization trial using the MART-1 and gp100 peptides in conjunction with incomplete Freund's adjuvant is in progress. These identified antigens may be useful for the development of new immunotherapies for the treatment of melanoma patients as well as for understanding the mechanisms of anti-tumor immune responses and autoimmune disorders against melanocytes. (Keio J Med 45 (2): 100-108, June 1996)
\end{abstract}

Key words: tumor antigens, T cells, MHC class I, cryptic self determinants, immunotherapy

\section{Introduction}

T-cells play an important role in tumor regression in vivo in many animal tumor models. In contrast to B cells which can only recognize surface proteins on tumor cells, $T$ cells can recognize peptides derived from intracellular proteins in tumor cells. In human melanoma, adoptive transfer of cultured cytotoxic T lymphocytes (CTL) derived from tumor infiltrating lymphocytes (TIL) resulted in tumor regression in $30-40 \%$ of patients. ${ }^{1,2}$ T-cell infiltrates in regressing tumors after IL2 based immunotherapies and the strong correlation between accumulation of injected $T$ cells in tumor sites and clinical response to TIL therapy suggested an important role of T-cells in in vivo melanoma rejection. ${ }^{3,4}$ The molecular nature of human melanoma antigens recognized by these autologous T-cells has recently been identified using genetic or biochemical techniques. Three strategies, 1) testing available candidate molecules, 2) isolation of peptides from HLA molecules on melanoma cells, 3) cloning genes encoding melanoma antigens, were used for the identification of melanoma antigens. ${ }^{5,6}$ The third method has been most successful in isolating tumor antigens. The isolated human melanoma antigens may be classified as 1) melanocyte specific melanosomal proteins (MART-1, gp100, tyrosinase and TRP-1), 2) testis specific proteins which are also expressed in a variety of cancers (MAGE-1, MAGE-3, BAGE and GAGE), 3) tumor specific mutated proteins ( $\beta$-catenin, MUM- 1 and CDK4), and 4 ) others (p15) (Table 1). In this review, we discuss these human melanoma antigens recognized by T-cells and their use for the treatment of patients with melanoma.

河上 裕

Presented at the 917th Meeting of The Kein Medical Society in Tokyo, May 12, 1995.

Reprint requests to: Dr Yutaka Kawakami, Surgery Branch, National Cancer Institute, National Institutes of Health, Bldg 10, Rm 2B42, 10 Center Dr, MSC 1502, Bethesda, MD 20892-1502, USA 
Table 1 Human Melanoma Antigens Recognized by T Cells

\begin{tabular}{|c|c|c|}
\hline Melanoma & Presenting MHC & Epitope \\
\hline \multicolumn{3}{|c|}{ Melanocyte Lineage Proteins } \\
\hline \multirow[t]{5}{*}{ gp100 } & HLA-A2 & KTWGQYWQV \\
\hline & HLA-A2 & ITDQVPFSV \\
\hline & HLA-A2 & YLEPGPVTA \\
\hline & HLA-A2 & LLDGTATLRL \\
\hline & HLA-A2 & VLYRYGSFSV \\
\hline \multirow[t]{2}{*}{ MART-1/Melan-A } & HLA-A2 & AAGIGILTV \\
\hline & HLA-A2 & ILTVILGVL \\
\hline TRP1 (gp75) & HLA-A31 & MSLQRQFLR \\
\hline \multirow[t]{5}{*}{ Tyrosinase } & HLA-A2 & MLLAVLYCL \\
\hline & HLA-A2 & YMNGTMSQV \\
\hline & HLA-B44 & SEIWRDIDF \\
\hline & HLA-A24 & AFLPWHRLF \\
\hline & HLA-DR4 & unknown \\
\hline \multicolumn{3}{|c|}{ Proteins Expressed in Testis and Other Cancers } \\
\hline \multirow[t]{2}{*}{ MAGE-1 } & HLA-A1 & EADPTGHSY \\
\hline & HLA-Cw16 & SAYGEPRKL \\
\hline \multirow[t]{2}{*}{ MAGE-3 } & HLA-A1 & EVDPIGHLY \\
\hline & HLA-A2 & FLWGPRALV \\
\hline BAGE & HLA-Cw16 & AARAVFLAL \\
\hline GAGE-1, 2 & HLA-Cw6 & YRPRPRRY \\
\hline \multicolumn{3}{|c|}{ Tumor Specific Antigens } \\
\hline$\beta$-Catenin & HLA-A24 & SYLDSGIHF \\
\hline MUM-1 & HLA-B44 & EEKLIVVLF \\
\hline CDK4 & HLA-A2 & ACDPHSGHFV \\
\hline \multicolumn{3}{|l|}{ Others } \\
\hline p15 & HLA-A24 & AYGLDFYIL \\
\hline
\end{tabular}

underline: mutation.

\section{Melanosomal Proteins}

Many cultured CTL recognize autologous melanoma cells in vitro as well as allogeneic melanoma cells and cultured melanocytes which share HLA class I molecules which present antigens, but do not recognize other types of tissue cells. ${ }^{5,7-11}$ A correlation between vitiligo development and melanoma regression after IL2 based immunotherapy was observed in the NCI Surgery Branch, and others have reported that vitiligo development correlates with a favorable prognosis or response to chemoimmunotherapy in melanoma patients. ${ }^{12-14}$ These observations suggest that autoreactive T-cells specific for non-mutated peptides derived from melanocyte/melanoma specific proteins may be involved in tumor regression. Four melanocyte/melanoma specific proteins (MART-1, gp100, tyrosinase and TRP-1) have been identified as antigens for $T$ cells. These proteins appear to be expressed in melanosomes and are involved in the synthesis of melanin pigment.

\section{Tyrosinase}

Tyrosinase was identified as a melanoma antigen by screening cDNA libraries using HLA-A2 restricted and HLA-A24 restricted, melanoma reactive CTL. ${ }^{15,16}$ Tyrosinase, a 529 amino acid melanosomal membrane protein, which has tyrosine hydroxylase, DOPA oxidase and DHI oxidase activity, and is involved in melanin synthesis. ${ }^{17}$ None of the HLA-A2 restricted TIL established in the NCI Surgery branch recognized tyrosinase, but HLA-A24 restricted TIL from 2 patients recognized tyrosinase. ${ }^{16,18}$ Adoptive transfer of one of the HLAA24 restricted tyrosinase reactive TIL into an autologous patient resulted in complete regression of tumor, suggesting that tyrosinase may be a tumor rejection antigen. Tyrosinase has also been shown to be recognized by HLA-DR4 restricted CD4+ melanoma reactive T cells derived from TIL. ${ }^{19}$ Two HLA-A2 binding epitopes, MLLAVLYCL and YMNGTMSQV, and one HLA-A24 binding epitope AFLPWHRLF have been identified. ${ }^{18,20}$ An HLA-B44 binding epitope SEIWRDIDF has recently been identified. ${ }^{21}$ Peptide-specific CTL could be induced by stimulation of PBL in five out of six donors with one of the HLA-A2 binding peptides, YMNGTMSQV, which had relatively high HLA-A2 binding affinity; however, only three of the five CTL lines were found to recognize HLA-A2 + melanomas. ${ }^{22}$ The high concentrations of peptides used to stimulate the in vitro response might induce $T$ cells bearing $T$ cell receptors with low affinity. These $T$ cells, while capable of recognizing cells pulsed with the peptide, can not recognize the relatively low levels of this peptide resulting from natural processing in melanoma cells.

\section{MART-1/Melan-A}

MART-1 (Melanoma Antigen Recognized by T-cells1)/Melan $A$ was isolated following the screening of a melanoma cDNA library with the HLA-A2 restricted melanoma-reactive CTL. ${ }^{9.23}$ MART-1 consists of 118 amino acids and contains a single putative transmembrane domain but does not appear to possess a signal sequence at the amino terminus. Northern blot analysis and immunohistochemical studies using anti-MART-1 antibody carried out on a variety of cell lines and tissues indicated that MART-1 was specifically expressed in most melanoma cell lines and melanocytes. Although the function of MART-1 is not yet known, melanocyte specific expression suggests that it may be involved in melanin synthesis.

MART-1 was found to be an immunodominant melanoma antigen and was shown to be recognized by the majority of HLA-A2 restricted melanoma reactive TIL established in the NCI Surgery Branch ${ }^{24}$ as well as by a large percentage of melanoma reactive $\mathrm{T}$ cell clones 
derived from the PBL of HLA-A2+ melanoma patients. ${ }^{25}$ By screening 28 MART-1 peptides (8-10-mers) synthesized on the basis of the HLA-A2.1 binding motifs, a 9-mer peptide, AAGIGILTV (M9-27) was identified as an epitope. This peptide was found to be an immunodominant epitope and was recognized by all HLA-A2 restricted MART-1 specific CTL. ${ }^{24}$ Another MART-1 epitope, ILTVILGVL, (M9-32) was isolated from HLAA2 molecules on melanoma cells. ${ }^{26}$ By stimulating PBL from melanoma patients with the M9-27 epitope potent melanoma reactive CTL could be generated. ${ }^{27}$ The cytolytic activity of the CTL generated in vitro with the M927 peptide was 50 to 100 fold greater than conventional TIL expanded with IL2 alone, indicating that these CTL may be useful for adoptive immunotherapy. Tumor regression was not observed in several patients who received the TIL reactive to MART-1. However, some evidence of tumor regression was observed in 3 of 23 patients who were immunized with the M9-27 peptide in conjunction with incomplete Freund's adjuvant in a recent clinical trial carried out in the NCI Surgery Branch, suggesting that the M9-27 peptide may represent a tumor rejection antigen.

\section{Gp100}

Gp100 was identified as a melanoma antigen for $\mathrm{T}$ cells by the three different methods described above. ${ }^{8,28,29}$ gp100 was found to represent the antigen recognized by melanoma reactive murine monoclonal antibody HMB 45 which is commonly used for the diagnosis of melanoma in pathology laboratories. ${ }^{30}$ gp100 is a membrane glycoprotein consisting of 661 amino acids with a leader sequence and a single transmembrane domain. gp100 was found predominantly in the membrane and filamentous matrix of melanosomes and is suspected to be involved in the late steps of melanin synthesis. ${ }^{31,32}$

Gp100, like MART-1, also appears to represent an immunodominant antigen, since it was recognized by many HLA-A2 restricted melanoma reactive CTL, ${ }^{24}$ and five gp100 epitopes have now been identified. ${ }^{33}$ Three of the gp100 epitopes, G9-154 (KTWGQYWQV), G9-209 (ITDQVPFSV), G9-280 (YLEPGPVTA) were recognized by CTL from different patients, suggesting that these represented immunodominant common epitopes. Melanoma reactive CTL could be induced by in vitro stimulation with these gp100 peptides, but not as efficiently as with the MART-1 peptide. ${ }^{34}$ Longer culture and more restimulations were necessary for the induction of melanoma reactive CTL with gp100 epitopes, indicating that the precursor frequency of CTL specific for the gp100 epitopes may be lower than the frequency of the MART-1-specific T cells. Somewhat paradoxically, the MART-1 M9-27 epitope has a lower HLA-A2 binding affinity than the gp100 epitopes. Conceivably, however, the gp100 peptides may be expressed at higher levels on the cell surface in vivo, than the MART-1 peptide, which could actually lead to partial tolerance induction. However, gp100 epitopes on melanoma cells were more efficiently recognized by activated gp100 specific T-cells. There was a correlation between the clinical response to TIL therapy and the recognition of gp100, but not MART-1, by TIL. ${ }^{33}$ In a clinical immunization protocol using G9-154, G9-209 or G9-280 peptide in conjunction with incomplete Freund's Adjuvant is ongoing in the Surgery Branch, NCI. The existence of multiple HLAA2 binding epitopes in gp100, probably related to its large size suggests that gp100 may contain more $T$ cell epitopes for various alleles of HLA. Thus, gp100 represents an attractive candidate antigen for the development of effective anti-tumor vaccines.

\section{$T R P 1$ (tyrosinase related protein-1, gp75)}

TRP1 was isolated by cDNA expression cloning techniques using an HLA-A31 restricted melanoma reactive CTL (35) which was administered to the autologous patient and induced tumor regression. ${ }^{36}$ TRP-1 was previously identified as an antigen recognized by IgG antibodies found in the serum of a patient with melanoma. ${ }^{37}$ Passive immunization with a mouse monoclonal antibody against murine TRP1 has recently been reported to result in tumor rejection of TRP1+ B16 murine melanoma. ${ }^{38}$ These results suggest that TRP1 may represent a good target for immunotherapy. TRP1 consists of 527 amino acids and is a melanosomal glycomembrane protein which has DHI-2-carboxylic acid oxidase activity involved in melanin synthesis. ${ }^{39}$ Surprisingly, the epitope MSLQRQFLR was not found in the TRP1 protein sequence, but instead, was found in an alternative open reading frame. ${ }^{40} \mathrm{~T}$ cell clones recognizing this epitope also recognized HLA-A31+ melanocytes as well as melanoma cells. Although the mechanism and generality of this phenomenon is not entirely clear, it is important to consider the possibility that $\mathrm{T}$ cells may recognize epitopes from alternative open reading frames.

\section{Proteins Expressed in Normal Testis and a Variety of Cancer}

This group of antigens contain the four proteins MAGE-1, MAGE-3, BAGE and GAGE, which have been isolated as melanoma antigens recognized by CTL clones established from a single melanoma patient who was repeatedly immunized with mutagenized autologous tumor celis. ${ }^{41}$

$M A G E$ family

MAGE-1 and its epitope EADPTGHSY was identified 
using an HLA-A1 restricted melanoma reactive CTL clone ${ }^{42,43}$ An additional MAGE-1 epitope SAYGEPRKL which was presented by HLA-Cw16 was also identified. ${ }^{44}$ In addition to normal testis, MAGE-1 was also expressed in approximately $40 \%$ of melanomas, as well as a smaller percentage of breast, lung, laryngeal, gastric cancers and sarcomas. Another member of the MAGE gene family, MAGE-3, was subsequently shown to be recognized by an HLA-A1 restricted CTL clone and EVDPIGHLY was identified as an epitope..$^{45,46}$ Since MAGE-3 is expressed in almost $70 \%$ of melanomas, this antigen may represent a better target for immunotherapy of melanoma than MAGE-1.

Although melanoma reactive CTL could be induced from the PBL of melanoma patients or normal donors by stimulation with the HLA-A1 binding epitope of MAGE-1 or MAGE-3, it was not as efficient as CTL induction with the MART-1 peptide. ${ }^{45.47}$ In one study, melanoma reactive CTL was generated from PBL of only one of six melanoma patients ${ }^{47}$ An HLA-A2 binding MAGE-3 peptide FLWGPRALV was identified by inducing CTL in vitro with this peptide. ${ }^{48}$ However, this CTL recognized melanoma cells only after they were treated with interferon- $\gamma$ which increased HLA expression. The role of MAGE in in vivo tumor rejection is unclear, however, active immunization trials using the MAGE- 1 and MAGE-3 HLA-A1 binding epitopes are in progress.

\section{$B A G E$ and $G A G E$}

BAGE and GAGE antigens were found to be expressed in a pattern similar to that found with members of the MAGE family and were isolated as melanoma antigens using $\mathrm{T}$ cells. ${ }^{49,50}$ An epitope AARAVFLAL recognized by an HLA-Cw16-restricted $T$ cell clone was identified. The GAGE was found to be a member of a multi-gene family, and two of the members of the family GAGE-1 and GAGE-2 were found to encode the peptide YRPRPRRY, which was recognized by the HLA-Cw6 restricted CTL. Expression of the GAGE gene was observed in $25 \%$ of sarcomas, $24 \%$ of melanomas, as well as a variety of additional cancers.

\section{Tumor-specific Antigens}

Since cancer cells accumulate many genetic changes, mutated peptides may be recognized by $\mathrm{T}$ cells as tumorspecific antigens. In melanoma, about $70 \%$ of patients responding to TIL therapy did not develop vitiligo and some $T$ cell clones appeared to recognize only autologous melanoma cells in vitro. These observations indicated the existence of tumor specific mutated peptides as melanoma antigens. Although the majority of melanoma epitopes so far identified are non-mutated normal self peptides, three mutated peptides derived from MUM-1, CDK4 and $\beta$-catenin have been identified as melanoma specific antigens.

\section{$M U M-1$}

The gene MUM-1 (melanoma ubiquitous mutated) was isolated using an HLA-B44 restricted melanoma reactive $C T L^{51}$ and appeared to be unrelated to any known genes. This gene was expressed in a variety of normal tissues such as liver, colon, muscle and heart. A single point mutation found in this sequence gave rise to the mutated peptide epitope containing a substitution from serine to isoleucine at a position in the sequence EEKLIVVLF. This epitope also appeared to spur an intron/exon boundary in an alternatively spliced gene product.

\section{$C D K 4$}

A mutated gene product ACDPHSGHFV derived from the cyclin-dependent kinase 4 gene (CDK4) was identified as a melanoma epitope recognized by HLAA2 restricted melanoma reactive $\mathrm{T}$ cell clones. ${ }^{52}$ This mutation is a $\mathrm{C}$ to $\mathrm{T}$ transition which is typically caused by UV irradiation, a major inducer of melanoma. ${ }^{53}$ The mutation was found to result in a change from an arginine to a cysteine at the primary anchor position of the HLA-A2.1 binding peptides. When the mutated epitope ACDPHSGHFV and the normal self peptide ARDPHSGHFV were tested for their ability to sensitize targets, the mutated peptide was found to sensitize HLAA2+ indicator cells at a 100 -fold to 1000 -fold lower concentration than that required for sensitization with the normal peptide. The mutated peptide, but not natural peptide, appeared to have high binding affinity for HLAA2. CDK4 forms a complex with cyclin D1 which promotes cell cycle progression from G1 to S phase. Binding of the mutated CDK4 to the CDK4 inhibitors p16INK4a and $\mathrm{p} 16 \mathrm{INK} 4 \mathrm{~b}$ as well as its kinase activity was reduced. Thus, this mutation in CDK4 may be involved in the malignant transformation of the melanoma cells.

\section{$\beta$-catenin}

$\beta$-catenin has recently been isolated using an HLAA24 restricted melanoma reactive TIL which induced complete tumor regression when administered into the autologous melanoma patient. ${ }^{54}$ The isolated cDNA was found to contain a single mutation $\mathrm{C}$ to $\mathrm{T}$ transition, which was also observed in the CDK4 gene, and this may represent another example of a UV-induced mutation. ${ }^{53}$ This mutation resulted in a change of amino acid residue from serine to phenylalanine in $P 9$ residue of the $T$ cell epitope, which created a typical HLA-A24 binding motif 
which contained tyrosine at the second position and phenylalanine at the last position. ${ }^{55}$ The mutated peptide SYLDSGIHF appeared to sensitize HLA-A24 expressing targets at $10^{6}$ fold lower concentration than the natural peptide. This appears to have resulted from the enhanced binding of the mutated epitope to HLA-A24. This newly created peptide with high HLA-A24 binding ability induced HLA-A24 restricted melanoma reactive CTL.

$\beta$-catenin has been shown to interact with the cellular adhesion molecule E-cadherin and the tumor suppresor gene APC product. Mutations of these proteins may be involved in generation of the tumor phenotype,$^{56}$ indicating that mutation of the $\beta$-catenin may be involved in oncogenesis in this melanoma. The identification of mutated epitopes as $\mathrm{T}$ cell antigens in CDK4 and $\beta$-catenin which may be involved in the tumor phenotype, suggest that these mutations may be important for the growth of these tumor cells.

p15

p15 was isolated using an HLA-A24-restricted TIL. ${ }^{57}$ This gene was expressed in most normal tissues and the identified T cell epitope, AYGLDFYIL, was encoded by a non-mutated gene. Since TIL used to isolate p15 does not recognize most cells which expressed p15, post transcriptional events such as a difference between antigen processing in tumor cells and normal cells may allow expression of this epitope only on the tumor cell surface.

\section{The Nature of Human Melanoma Antigens Recognized by T Cells}

Both normal self peptides and tumor specific mutated peptides were identified as human melanoma antigens recognized by $\mathrm{T}$ cells. However, all of the melanoma epitopes identified in melanosomal proteins as well as testis specific proteins represented non-mutated self peptides (Table 1). MAGE, BAGE, and GAGE were isolated using CTL derived from a single patient who was repeatedly immunized with mutagenized melanoma cells and thus may not represent antigens which are normally recognized by $T$ cells from most patients. Self peptides derived from melanosomal proteins, however, appear to represent highly immunogenic antigens, since they are recognized by T-cells derived from many patients. ${ }^{24}$ One question raised by these results is why $\mathrm{T}$ cells which recognize mutated peptides do not predominate. It may be related to the high immunogenic nature of melanosomal proteins. It has been reported that p53 mutations were not found in the regions encoding HLA-A2 binding peptides in HLA-A2+ lung cancer cells, suggesting that tumor cells expressing HLA-A2 binding mutated p53 peptides may have been eliminated before by T-cells. ${ }^{58}$ Melanoma cells which express highly immunogenic mutated peptides may be generally eliminated by immunosurveillance.

In order to evaluate the immunological nature of nonmutated melanoma epitopes, the HLA-A2 binding T cell epitopes identified in the melanoma antigens were evaluated for their MHC binding affinity and the ability to induce CTL responses in vitro. In contrast to peptides isolated from HLA-A2 on cells or previously identified viral epitopes, most of which contained leucine or methionine at the second positon (P2) and valine at the C-terminus (P9) (dominant anchor amino acids in HLAA2.1 binding motif) and had actually high binding affinity to HLA-A2.1, ${ }^{59-62}$ melanoma epitopes generally contained non-dominant amino acids at the primary anchor positions (alanine or threonine at P2 of AAGIGILTV, KTWGQYWQV and ITDQVPFSV, and alanine at P9 of YLEPGPVTA) and possessed relatively low (intermediate) binding affinity for HLA-A2 (Table 2 ). ${ }^{33}$ These results indicate that it may be important to screen peptides which contain non-dominant anchor amino acids and have intermediate $\mathrm{MHC}$ binding affinity when attempting to identify tumor antigenic epitopes. ${ }^{33}$ Binding affinity is one of the major factors influencing the cell surface density of epitopes along with other factors including the amount of protein and efficiency of enzymatic cleavage and peptide transport to the endoplasmic reticulum. These results suggest that melanoma epitopes may be subdominant or cryptic self determinants which are expressed at very low density on cell surfaces and for which tolerance is not completely induced. ${ }^{63-65}$ When PBL from melanoma patients were stimulated to induce CTL in vitro with a number of MART-1 peptides which had various HLA-A2 binding affinities, CTL could be induced only with peptides which had intermediate affinities, but not with high affinity peptides. ${ }^{27} \mathrm{~T}$ cells specific for high affinity peptides may be tolerized by normal cells such as melanocytes which express these peptides at high density on the cell surface. Murine experiments

Table 2 HLA-A2 Binding Mclanoma Epitopes

\begin{tabular}{lll}
\hline \hline Antigen & Epitope & $\begin{array}{l}\text { HLA-A2 } \\
\text { Binding Affinity }\end{array}$ \\
\hline gp100 & KTWGQYWQV & high \\
& ITDQVPFSV & intermediate \\
& YLEPGPVTA & intermediate \\
& LLDGTATLRL & intermediate \\
& VLYRYGSFSV & high \\
MART-1 & ALAGIGILTV & intermediate \\
& ILTVILGVL & intermediate \\
Tyrosinase & MLLAVLYCL & intermediate \\
& YMNGTMSQV & high \\
\hline
\end{tabular}

Underline: Non-dominant amino acids at primary anchor positions. 
have suggested that $T$ cell tolerance was induced only to peptides which appeared to be expressed at high density on the cell surface (dominant self-determinants) ${ }^{63,66}$

These CTL specific for cryptic determinants which were usually silent were tumor reactive. Overexpression of antigen or MHC molecules on tumor cells might increase expression of these epitopes on cell surfaces and tissue destruction and inflammation around tumors might induce cytokines which activate anti-tumor $\mathrm{T}$ cells directly or augment the expression of $\mathrm{MHC}$ /antigen and adhesion molecules necessary for $\mathrm{T}$-cell activation. These in vivo antigen primed CTL might be further activated and expanded in vitro when cultured with IL2.

\section{Immunotherapy of Patients with Melanoma Using the Identified Melanoma Antigens}

Mutated peptides which are expressed in one or a small number of patients' tumors may be difficult to use for immunotherapy unless they are common mutations or new techniques are developed for the rapid identification of tumor antigens. Non-mutated epitopes, particularly HLA-A2 binding epitopes (HLA-A2 is expressed in about a half of patients) appear to be most useful for immunotherapy. When these normal self peptides are used for immunotherapy, autoimmune problems may occur similar to Vogt-Koyanagi-Harada syndrome which represents an autoimmune disease against melanocytes. Patients may develop symptoms such as vitiligo, poliosis, uveitis, dysacusis or meningismus as a result of melanocyte destruction. ${ }^{67}$ However, dramatic tumor regression was observed in some patients who received TIL therapy only with occasional vitiligo. ${ }^{8}$ Therefore, autoreactive $\mathrm{T}$ cell responses can be used for the treatment of melanoma patients without severe adverse effects on normal melanocytes. ${ }^{64,65,68,69}$

In order to induce $T$-cells specific for cryptic self epitopes, the use of methods which allow high expression of these epitopes on the antigen presenting cell (APC) surface is important (Table 3). ${ }^{64,65}$ This may be accomplished through the use of systems which result in high levels of expression such as recombinant viral vectors containing tumor antigen genes, or by exogenous peptide loading on APC. Recombinant vaccinia virus, fowlpox virus and adenovirus containing MART-1 or gp100 have been constructed and will be used in clinical trials in the NCI Surgery branch. ${ }^{70}$ Viral vectors have potential risks and it may be difficult to boost immune response because anti-viral T-cell responses may decrease the efficacy of subsequent immunizations. Immunization with "naked DNA" is safe and repeatedly usable, however, the efficacy of immunization is weaker than with recombinant viruses. ${ }^{71}$ Peptides may be used for immunization in conjunction with adjuvants or lipids. ${ }^{72}$ Clinical
Table 3 Reagents for Active Immunization of Cancer Patients

1. Antigenic peptides or whole proteins (with adjuvants, combined with lipids or liposomes, with gp96, Hsp70 or Hsp90)

2. Recombinant viruses containing tumor antigen genes (adenovirus, fowlpox virus, vaccinia virus)

3. Naked DNA encoding tumor antigen genes (intramuscular or by "gene gun")

4. Recombinant bacteria containing tumor antigen genes (BCG, Salmonella, Listeria)

5. Cells expressing tumor antigens (dendritic cells pulsed with epitopes, cells transfected with tumor antigens, HLA and B7 genes, cells transfected with epitope/HLA fusion genes)

6. Cytokines augumenting immunization (IL2, IL12)

trials using MART-1 or gp100 peptides along with incomplete Freund's adjuvant are being conducted in melanoma patients in the NCI Surgery Branch. Some evidence of tumor regression has been observed in 3 of 23 melanoma patients who were immunized with the MART-1 M9-27 peptide. In addition, professional APC such as dendritic cells pulsed with the peptides may be used as immunogens. Heatshock proteins such as gp96, hsp90 or hsp70 may be useful as peptide delivery vehicles for APC. ${ }^{73}$ Potent melanoma reactive T-cells more $(\sim 50$ fold) than the conventional CTL established from TIL by culturing with IL2 could be induced from the PBL of patients by repeated stimulation with PBMC pulsed with the melanoma epitopes. ${ }^{27}$ These CTL may be more effective if used for adoptive transfer protocols.

Since many melanoma epitopes have relatively low MHC binding affinity and MHC binding affinity usually correlates with the immunogenicity of epitopes in the case of foreign antigens, ${ }^{74}$ the natural melanoma epitopes may not be efficient immunogens. By changing amino acids of melanoma epitopes, particularly at primary anchor positions, we could make peptides which had significantly better HLA-A2 binding ability and could induce melanoma reactive CTL in vitro more efficiently than the native epitopes. ${ }^{75}$ For example, the G9-280-9V peptide in which alanine at $\mathrm{P} 9$ was substituted to valine could induce potent melanoma reactive CTL from PBL of all 7 patients tested, whereas the natural G9-280 peptide could induce weak melanoma reactive CTL only in 2 of 7 patients. The G9-209-2M peptide in which threonine was replaced with methionine at $\mathbf{P} 2$ could also induce melanoma reactive CTL more efficiently than the native G9209 peptide. Therefore, these modified peptides are more immunogenic and may be useful for the induction of melanoma reactive T-cells in vitro and in vivo. Clinical trials using these modified peptides is in progress in the 
NCI Surgery branch. These amino acid changes may also be incorporated in the gp $100 \mathrm{cDNA}$ which could be used for the construction of recombinant viruses or naked DNA vaccines. Since the concept of the modified peptides which induce T-cells specific for cryptic self determinants is similar to the concept of molecular mimicry of foreign peptides to initiate autoimmune diseases, these modified peptides may also induce more autoimmune problems. Another system which results in expression of melanoma epitopes on APC surface at high density is also being exploited. Melanoma epitopes have been covalently linked to HLA-A2.1 molecules with a spacer to prevent dissociation of peptides from the groove of HLA-A2 molecules. Melanoma reactive CTL could be induced in vitro from PBL by stimulation of B-cells transfected with this MART-1 M9-27 epitope-HLA-A2.1 fusion DNA (Kang XQ et al, unpublished data).

Administration of cytokines such as IL2, IL12 or interferon may increase the efficacy of immunotherapies by improving immunization as well as improve tumor recognition at the effector phase by increasing epitope/ MHC complexes on the tumor cell surface. ${ }^{71,76}$

Since melanocytes and melanoma cells may tolerize T-cells in vivo, ${ }^{77}$ repeated immunization may be necessary to induce complete regression of tumors. In order to maintain anti-tumor $\mathrm{T}$ cell response it may be necessary to sequentially immunize patients with multiple antigens using different immunization methods. In addition, as tumor cells may escape from $T$ cell recognition by a variety of mechanisms including loss of antigens, $\mathrm{MHC}$, $\beta 2$-microglobulin or altered antigen processing ability, ${ }^{78}$ it may be important to combine, with immunotherapy, therapies with different anti-tumor mechanisms such as chemotherapy.

\section{References}

1. Rosenberg SA, Packard BS, Aebersold PM, Solomon D, Topalian SL, Toy ST, Simon P, Lotze MT, Yang JC, Seipp CA, Simpson C, Carter C, Bock S, Schwartzentruber D, Wei JP, White DE: Use of tumor infiltrating lymphocytes and interleukin-2 in the immunotherapy of patients with metastatic melanoma. Preliminary report. N Engl J Med 1988, 319: 1676-1680

2. Rosenberg SA, Yannelli JR, Yang JC, Tpopalian SL, Schwartzentruber DJ, Weber JS, Parkinson DR, Seipp CA, Einhorn JH, White DE: Treatment of patients with metastatic melanojma with autologous tumor-infiltrating lymphocytes and interleukin 2 . J Natl Cancer Inst 1995, 86: 1159-1166

3. Rubin JT, Elwood LJ, Rosenberg SA, Lotze MT: Immunohistochemical correlates of response to recombinant interleukin-2 based immunotherapy in humans. Cancer Res 1989, 49: 70867092

4. Pockaj BA, Sherry R, Wei J, Yannelli JR, Cartcr CS, Leitman SF, Carrasquillo JR, White DE, Steinberg S, Rosenberg SA, Yang JD: Localization of Indium-111-labelled tumor infiltrating lymphocytes to tumor in patients receiving adoptive immunotherapy: augmentation with cyclophosphamide in association with response. Cancer 1994, 73: 1731-1737
5. Kawakami Y, Nishimura I, Restifo NP, Topalian SL, O'Neil BH, Shilyansky J, Yannelli JR, Rosenberg SA: T-cell recognition of human melanoma antigens. J Immunother 1993, 14: 88-93

6. Kawakami Y, Robbins P, Wang RF, Rosenberg SA: Identification of tumor regression antigens in melanoma. Important Adv Oncol 1996: 3-21

7. Anichini A, Maccalli C, Mortarini R, Salvi S, Mazzocchi A, Squarcina P, Herlyn M, Parmiani G: Melanoma cells and normal melanocytes share antigens recognized by HLA-A2 restricted cytotoxic T cell clones from melanoma patients. J Exp Med 1993, 177: 989-998

8. Kawakami Y, Eliyahu S, Delgado $\mathrm{CH}$, Robbins PF, Sakaguchi K, Appella E, Yannelli JR, Adema GJ, Miki T, Rosenberg SA: Identification of a human melanoma antigen recognized by tumor infiltrating lymphocytes associated with in vivo tumor rejection. Proc Natl Acad Sci USA 1994, 91: 6458-6462

9. Kawakami Y, Eliyahu S, Delgaldo CH, Robbins PF, Rivoltini L, Topalian SL, Miki T, Rosenberg SA: Cloning of the gene coding for a shared human melanoma antigen recognized by autologous T cells infiltrating into tumor. Proc Natl Acad Sci USA 1994, 91: 3515-3519

10. Kawakami Y, Zakut R, Topalian SL, Stotter H, Rosenberg SA: Shared human melanoma antigens. Recognition by tumor infiltrating lymphocytes in HLA-A2.1 transfected melanomas. J Immunol 1992, 148: 639-643

11. O'Neil BH, Kawakami Y, Restifo NP, Bennink JR, Yewdell JW Rosenberg SA: Detection of shared MHC-restricted human melanoma antigens after vaccinia virus-mediated transduction of genes coding for HLA. J Immunol 1993, 1410: 1418-1993

12. Nordlund JJ, Kirkwood JM, Forget BM, Milton G, Albert DM, Lerner AB: Vitiligo in patients with metastatic melanoma: a good prognostic sign. J Am Acad Dermatol 1983, 9: 689-695

13. Bystryn JC, Rigel D, Friedman RJ, Kopf A: Prognostic significance of hypopigmentation in malignant melanoma. Arch Dermatol 1987, 123: 1053-1055

14. Richards JM. Mehta N, Ramming K, Skosey P: Sequential chemoimmunotherapy in the treatment of metastatic melanoma. J Clin Oncol 1992, 10: 1338-1343

15. Brichard V, Van Pel A, Wölfel T, Wölfel C, De Plaen E, Lethë $B$, Coulie P, Boon T: The tyrosinase gene codes for an antigen recognized by autologous cytolytic T lymphocytes on HLA-A2 melanomas. J Exp Med 1993, 178: 489-495

16. Robbins PF, El-Gamil M, Kawakami Y, Stevens E, Yannelli J, Rosenberg SA: Recognition of tyrosinase by tumor infiltrating lymphocytes from a patient responding to immunotherapy. Cancer Res 1994, 54: 3124-3126

17. Bouchard B, Fuller BB, Vijayasaradhi S, Houghton AN: Induction of pigmentation in mouse fibroblasts by expression of human tyrosinase cDNA. J Exp Med 1989, 169: 2029-2042

18. Kang XQ, Kawakami Y, Sakaguchi K, El-Gamil M, Wang RF, Yannelli JR, Appella E, Rosenberg SA, Robbins PF: Identification of a tyrosinace epitope recognized by HLA-A24 restricted tumor-infiltrating lymphocytes. J Immunol 1995, 155: 1343-1348

19. Topalian SL, Rivoltini L, Mancini M, Markus NR, Robbins PF, Kawakami Y, Rosenberg SA: Human CD4+ T cells specifically recognize a shared melanoma - associated antigen encoded by the tyrosinase gene. Proc Natl Acad Sci USA 1994, 91: 94619465

20. Wolfel T, Van Pel A, Brichard V, Schneider J, Seliger B, Meyer zum Buschenfelde KH, Boon T: Two tyrosinase nonapeptides recognized on HLA-A2 melanomas by autologous cytolytic $T$ lymphocytes. Eur J Immunol 1994, 24: 759-764

21. Van Pel A, van der Brugen P, Coulie PG, Brichard VG, Lethe B, van der Eynde B, Uyttenhove C, Renauld JC, Boon B: Genes coding for tumor antigens recognized by cytolytic $\mathrm{T}$ lymphocytes. Immunol Rev 1995, 145: 229-250 
22. Visseren MJ, van Elsas A, van der Voort EIH, Ressing ME, Kast WM, Schrier PI, Melief CJM: CTL specific for the tyrosinase autoantigen can be induced from healthy donor blood to lyse melanoma cells. J Immunol 1995, 154: 3991-3998

23. Coulie PG, Brichard V, Van Pel A, Wolfel T, Schneider J, Traversari C, Mattei S, De Plaen ED, Lurquin C, Szikora JP, Reauld JC, Boon T: A new gene coding for a differentiation antigen recognized by autologous cytolytic $T$ lymphocytes on HLA-A2 melanomas. J Exp Med 1994, 180: 35-42

24. Kawakami Y, Eliyahu S, Sakaguchi K, Robbins PF, Rivoltini L, Yannelli JR, Appella E, Rosenberg SA: Identification of the immunodominant peptides of the MART-1 human melanoma antigen recognized by the majority of HLA-A2 restricted tumor infiltrating lymphocytes. J Exp Med 1994, 180: 347-352

25. Sensi M, Traversari C, Radrizzani M, Salvi S, Maccalli C, Mortarini R, Rivoltini L, Farina C, Nicolini G, Wolfel T, Brichard V, Boon T, Bordignon C, Anichini A, Parmiani G: Cytotoxic T lymphocyte clones from different patients display limited $\mathrm{T}$-cell receptors variable gene usage in HLA-A2 restricted recognition of Melan/Mart-1 melanoma antigen. Proc Natl Acad Sci USA 1995, 92: 5674-5678

26. Castelli C, Storkus WJ, Maeurer MJ, Martin DM, Huang EC, Pramanik BN, Nagabhushan TL, Parmiani G, Lotze MT: Mass spectrometric identification of a naturally processed melanoma peptide recognized by CD8+ cytotoxic T lymphocytes. J Exp Med 1994, 181: 363-368

27. Rivoltini L, Kawakami Y, Sakaguchi K, Southwood S, Sette A, Robbins PF, Marincola FM, Salgaller ML, Yannelli JR, Appella E, Rosenberg SA: Induction of tumor-reactive CTL from peripheral blood and tumor-infiltrating lymphocytes of melanoma patients by in vitro stimulation with an immunodominant peptide of the human melanoma antigen MART-1. J Immunol 1995, 154: 2257-2265

28. Bakker AB, Schreurs MW, De Boer AJ, Kawakami Y, Rosenberg SA, Adema GJ, Figdor CG: Melanocyte lineage-specific antigen gp100 is recognized by melanocyte-derived tumor-infiltrating lymphocytes. J Exp Med 1994, 179: 1005-1009

29. Cox AL, Skipper J, Cehn Y, Henderson RA, Darrow TL, Shabanowitz J, Engelhard VH, Hunt DF, Slingluff CL: Identification of a peptide recognized by five melanoma-specific human cytotoxic T cell lines. Science 1994, 264: 716-719

30. Adema GJ, de Boer AJ, van't Hullenaar R, Denijn M, Ruiter DJ, Vogel AM, Figdor CG: Melanocyte lineage-specific antigens recognized by monoclonal antibodies NK1- $\beta \mathrm{b}$, HMB-50, and HMB-45 are encoded by a single cDNA. Am J Pathol 1993, 143: 1579-1585

31. Schaumburg-Lever G, Metzler G, Kaiserling E: Ultrastructural localization of HMB45 binding sites. J Cutan Pathol 1991, 18 : $432-435$

32. Kobayashi T, Urabe K, Orlow SJ, Higashi K, Imokawa G, Kwon BS, Potterf B, Hearing VJ: The Pme117/Silver locus protein, characterization and investigation of its melanogenic function. J Biol Chem 1994, 269: 29198-29205

33. Kawakami Y, Eliyahu S, Jennings C, Sakaguchi K, Kang XQ, Southwood S, Robbins PF, Sette A, Appella E, Rosenberg SA: Recognition of multiple epitopes in the human melanoma antigen gp100 associated with in vivo tumor regression. J Immunol 1995, 154: $3961-3968$

34. Salgaller ML, Afshar A, Marincola FM, Rivoltini L, Kawakami Y, Rosenberg SA: Recognition of multiple epitopes in the human melanoma antigen gp100 by peripheral blood lymphocytes stimulated in vitro with synthetic peptides. Cancer Res 1995, 55: 49724979

35. Wang RF, Robbins PF, Kawakami Y, Kang XQ, Rosenberg SA: Identification of a gene encoding a melanoma tumor antigen recognized by HLA-A31-restricted tumor-infiltrating lymphocytes.
J Exp Med 1995, 181: 799-804

36. Topalian S, Solomon D, Avis FP, Chang AE, Freeksen DL, Linehan WM, Lotze MT, Robertson CN, Seipp CA, Simon P. Simpson CG, Rosenberg SA: Immunotherapy of patients with advanced cancer using tumor infiltrating lymphocytes and recombinant interleukin-2: a pilot study. J Clin Oncol 1988, 6: 839-853

37. Mattes MJ, Thomson TM, Old LJ, Lloyd KO: A pigmentationassociated, differentiation antigen of human melanoma defined by a precipitating antibody in human serum. Int J Cancer 1983, 32: $717-721$

38. Hara I, Takechi Y, Houghton AN: Implicating a role for immune recognition of self in tumor rejection: passive immunization against the Brown locus protein. J Exp Med 1995, 182: 1609-1614

39. Jimenez-Cervantes C, Solano F, Kobayashi T, Urabe K, Hearing VJ, Lozano JA, Garcia-Borron JC: A new enzymatic function in the melanogenic pathway. J Biol Chem 1994, 269: 17993-18001

40. Wang R, Parkhurst MR, Kawakami X, Robbins PF, Rosenberg SA: Utilization of an alternative open reading frame of a normal gene in generating human cancer antigen. J Exp Med 1996, 183: $1131-1140$

41. Van Den Eynde B, Hainaut $P$, Hërin $M$, Knuth A, Lemoine C, Weynants P, Van der Bruggen P, Fauchet R, Boon T: Presence on a human melanoma of multiple antigens recognized by autologous CTL. Int J Cancer 1989, 44: 634-640

42. Van der Bruggen $P$, Traversari C, Chomez $P$, Lurquin C, DePlaen E, Van Den Eynde B, Knuth A, Boon T: A gene encoding an antigen recognized by cytolytic $\mathrm{T}$ lymphocytes on a human melanoma. Science 1991, 254: 1643-1647

43. Traversari $C$, Van der Bruggen $P$, Luescher IF, Lurquin $C$, Chomez P, Van Pel A, De Plaen E, Amar-Costesec A, Boon T: A nonapeptide encoded by human gene MAGE-1 is recognized on HLA-A1 by cytolytic T lymphocytes directed against tumor antigen MZ2-E. J Exp Med 1992, 176: 1453-1457

44. Van der Bruggen P, Szikora JP, Boel P, Wildmann C, Somville M, Sensi M, Boon T: Autologous cytolytic T lymphocytes recognized a MAGE-1 nonapeptide on melanomas expressing Cw1601. Eur J Immunol 1994, 24: 2134-2140

45. Celis E, Tsai V, Crimi C, DeMars R, Wentworth PA, Chestnut RW, Grey HM, Sette A, Serra HM: Induction of anti-tumor cytotoxic $\mathrm{T}$ lymphocytes in normal humans using primary cultures and synthetic peptide epitopes. Proc Natl Acad Sci USA 1994, 91: 2105-2109

46. Gaugler B, Van Den Eynde B, Van der Bruggen P, Romero P Gaforio JJ, De Placn E, Lethe B, Brasseur F, Boon T: Human gene MAGE- 3 codes for an antigen recognized on a melanoma by autologous cytolytic T lymphocytes. J Exp Med 1994, 179: 921930

47. Salgaller ML, Weber JS, Koenig S, Yanelli JR, Rosenberg SA Generation of specific anti-melanoma reactivity by stimulation of human tumor-infiltrating lymphocytes with MAGE-1 synthetic peptide. Cancer Immunol Immunothr 1994, 39: 105-116

48. Van der Bruggen P, Bastin J, Gajewski T, Coulie PG, Boel P, de Smet C. Traversari C, Townsend A, Boon T: A peptide encoded by human gene MAGE-3 and presented by HLA-A2 induces cytolytic $\mathbf{T}$ lymphocytes that recognize tumor cells expressing MAGE-3. Eur J Immunol 1994, 24: 3038-3043

49. Boel P, Wildmann C, Sensi ML, Brasseur R, Renauld JC, Coulie $P$, Boon T, Van der Bruggen P: BAGE: a new gene encoding an antigen recognized on human melanomas by cytolytic $\mathbf{T}$ lymphocytes. Immunity 1995, 2: 167-175

50. Van Den Eynde B, Peetcrs O, De Backer O, Gaugler B, Lucas S, Boon T: A new family of genes coding for an antigen recognized by autologous cytolytic $\mathrm{T}$ lymphocytes on a human melanoma. J Exp Med 1995, 182: 689-698

51. Coulie PG, Lehmann F, Lethe B, Herman J, Lurquin C Andrawiss $\mathrm{M}$, Boon $\mathrm{T}$ : A mutated intron sequence codes for an 
antigenic peptide recognized by cytolytic $T$ lymphocytes on a human melanoma. Proc Natl Acad Sci USA 1995, 92: 7976-7980

52. Wolfel T, Hauer M, Schneider J, Serrano M, Wolfel C, KlehmannHieb E, De Plaen E, Hankeln T, Meyer zum Buschenfelde KH, Beach D: A p16INK4a-insensitive CDK4 mutant targeted by cytolytic T lymphocytes in a human melanoma. Science 1995, 269: 1281-1284

53. Brash DE, Rudolph JA, Lin A, McKenna GJ, Baden HP, Halperin AJ, Ponten J: A role of sunlight in skin cancer: UVinduced p53 mutations in squamous cell carcinoma. Proc Natl Acad Sci USA 1991, 88: 10124-10128

54. Robbins PF, El-Gamil M. Li YF, Kawakami Y, Loftus D, Appella E, Rosenberg SA: A mutated $\beta$-catenin gene encodes a melanomaspecific antigen recognized by tumor infiltrating lymphocytes. J Exp Med 1996, 183: 1185-1192

55. Kubo RT, Sette A, Grey HM, Appella E, Sakaguchi K, Zhu NZ, Arnott D, Sherman N, Shabanowitz J, Michel H, Bodnar WM, Davis TA, Hunt DF: Definition of specific peptide motifs for four major HLA-A alleles. J Immunol 1994, 152: 3913-3924

56. Kawanishi J, Kato J, Sasaki K, Fujii S, Watanabe M, Niitsu Y: Loss of E-cadherin-dependent cell-cell adhesion due to mutation of the $\beta$-catenin gene in a human cancer cell line, HSC-39. Mol Cell Biol 1995, 15: 1175-1181

57. Robbins PF, El-Gamil M, Li YF, Topalian SL, Rivoltini L, Sakaguchi K, Appella E, Kawakami Y, Rosenberg SA: Cloning of a new gene encoding an antigen recognized by melanomaspecific HLA-A24 restricted tumor-infiltrating lymphocytes. J Immunol 1995, 154: 5944-5950

58. Wiedenfeld EA, Fernandez-Vina M, Berzofsky JA, Carbone DP: Evidence for selection against human lung cancers bearing p53 missense mutations which occur within the HLA A-0201 peptide consensus motif. Cancer Res 1994, 54: 1175-1177

59. Falk K, Rotzschke O, Stevanovic S, Jung G, Rammensee HG: Allele-specific motifs revealed by scquencing of self-peptides eluted from MHC molecules. Nature 1993, 351: 290-296

60. Hunt DF, Henderson RA, Shabanowitz J, Sakaguchi K, Michel H. Sevilir N, Cox AL, Appella E, Engelhard VH: Characterization of peptides bound to the Class I MHC molecule HLAA2.1 by mass spectrometry. Science 1992, 255: 1261-1263

61. Sette A, Vitiello A, Reherman B, Fowler P, Nayersina R, Kast WM, Melief CJ, Oseroff C, Yuan L, Ruppert J: The relationship between class I binding affinity and immunogenicity of potential cytotoxic T cell epitopes. J Immunol 1994, 153: 5586-5592

62. Parker KC, Shields M, DiBrino M, Brooks A, Coligan JE: Peptide binding to MHC class I molecules: implications for antigenic peptide prediction. Immunol Res 1995, 14: 34-57

63. Sercarz EE, Lehmann PV, Ametani A, Benichou G, Miller A, Moudgil K: Dominance and crypticity of $T$ cell antigenic determinants. Annu Rev Immunol 1993, 11: 729-766

64. Kawakami Y, Rosenberg SA: Immunobiology of human melanoma antigens MART-1 and gp100 and their use for immuno-gene therapy. Intern Rev Immunol (in press)

65. Kawakami Y, Rosenberg S: T-cell recognition of self peptides as tumor rejection antigens. Immunol Res (in press)

66. Moudgil KD, Ametani A, Grewal IS, Kumar V, Sercarz EE: Processing of self-proteins and its impact on shaping the $T$ cell repertoire, autoimmunity and immune regulation. Intern $\operatorname{Rev}$ Immunol 1993, 10: 365-377

67. Chan CC, Palestine AG, Nussenblatt RB: Sympathetic ophthalmia and Vogt-Koyanagi-Harada syndrome. In: Tasman W, Jaeger EA, eds, Duane's Clinical Ophthalmology, Philadelphia, J.B. Lippincott Co, 1989

68. Moudgil KD, Sercarz EE: Can antitumor immune responses discriminate between self and nonself? Immunol Today 1994, 15: 353-355

69. Nanda NK, Sercarz EE: Induction of anti-self-immunity to cure cancer. Cell 1995, 82: 13-17

70. Zhai Y, Yang JC, Kawakami Y, Spiess P. Wadsworth SC, Cardoza LM, Coutune LA, Smith AE, Rosenberg SA: Antigen-specific tumor vaccines: development and characterization of recombinant adenoviruses encoding MART-1 or gp100 for cancer therapy. J Immunol 1996, 156: 700-710

71. Irvine K, Rao J, Rosenberg S, Restifo N: Cytokine enhancement of DNA immunization leads to treatment of established pulmonary metastases. J Immunol 1996, 156: 238-245

72. Minev B, McFarland BJ, Spiess PJ, Rosenberg SA, Restifo NP: Insertion signal sequence fused to minimal peptides elicits specific CD8+ T-cell responses and prolong survival of thymoma-bearing mice. Cancer Res 1994, 54: 4155-4161

73. Suto R, Srivastava PK: A mechanism for the specific immunogenicity of heat shock protein-chaperoned peptides. Science 1995, 269: $1585-1588$

74. Chen W, Khilko S, Fecondo J, Margulies DH, McClusky J: Determinant selection of major histocompatibility complex class I-restricted antigenic peptides is explained by class I-peptide affinity and is strongly influenced by nondominant anchor residues. J Exp Med 1994, 180: 1471-1483

75. Parkhurst MR, Salgaller M, Southwood S, Robbins P, Sette A, Rosenberg SA, Kawakami Y: Improved induction of melanoma reactive CTL with peptides from the melanoma antigen gp 100 modified at HLA-A0201 binding residues. J Immunol (in press)

76. Bronte V, Tsung K, Rao JB, Chen PW, Wang M, Rosenberg SA, Restifo NP: IL-2 enhances the function of recombinant poxvirusbased vaccines in the treatment of established pulmonary metastases. J Immunol 1995, 154: 5282-5292

77. Matzinger P: Tolerance, danger, and the extended family. Annu Rev Immunol 1994, 12: 991-1045

78. Restifo NP, Kawakami Y, Marincola F, Shamamian P, Taggarse A, Esquive IF, Rosenberg SA: Molecular mechanisms used by tumors to escape immune recognition: immunogentherapy and the cell biology of major histocompatibility complex Class I. J Immunother 1993, 14: 182-190 